\title{
Input Chains and Industrialization
}

by

Antonio Ciccone*

November 2000

\begin{abstract}
A key aspect of industrialization is the adoption of increasing-returns-to-scale, industrial, technologies. Two other, well-documented aspects are that industrial technologies are adopted throughout intermediate-input chains and that they use intermediate inputs intensively relative to the technologies they replace. These features of industrial technologies combined imply that countries with access to similar technologies may have very different levels of industrialization and income, even if the degree of increasing returns to scale at the firm level is relatively small. Furthermore, a small improvement in the productivity of industrial technologies can trigger fullscale industrialization and a large increase in income.
\end{abstract}

JEL Classification: O11, O14, O21.

Keywords: Intermediate Inputs, Input Chains, Industrialization, Aggregate-Income Differences.

*Universitat Pompeu Fabra, Department of Economics and Business, Ramon Trias Fargas 25-27, 08005 Barcelona, Spain. The paper combines "The Acceleration Principle, Income Generation, and Industrialization" and "The Statics and Dynamics of Industrialization and Specialization" both first circulated in February 1993. Thanks to Gary Richardson, Ilya Segal, and David Romer for their comments on these earlier versions. Thanks also to two referees and two editors for comments that helped to much improve the current version of the paper. 


\section{$1 \quad$ Introduction}

It is often maintained that many countries have achieved high levels of aggregate income through industrialization, and that the main aspect of industrialization is the widespread adoption of increasing-returns-to-scale, industrial, technologies. A prominent formulation of this view can be found in Murphy, Shleifer, and Vishny (1989), whose theoretical analysis focuses on the adoption of industrial technologies in final-goods production only. Their conclusions confirm Fleming's (1955) argument that this narrow view of industrialization alone can neither explain why countries with access to similar technologies may have very different levels of industrialization and income, nor why a small improvement in industrial technologies may trigger full-scale industrialization and a large increase in income. Furthermore, their analysis yields that the increase in aggregate income that can be explained by this view of industrialization is smaller than the productivity-increase at the firm level. This upper bound makes it difficult to attribute high levels of income to industrialization as empirical evidence suggests that increasing returns at the firm level are relatively small. ${ }^{1}$

Two other, well-documented aspects of industrialization are that industrial technologies are adopted throughout intermediate-input chains in the economy, and that industrial technologies use intermediate inputs intensively relative to the technologies they replace. For example, one of the empirical regularities found in Chenery, Robinson, and Syrquin (1986) - the most detailed comparative study of industrialization available - is that intermediate inputs' share of the value of manufacturing production increases with industrialization. For example, their data show that this share tripled between 1956 and 1971 in Taiwan and rose rapidly with industrialization in Israel,

\footnotetext{
${ }^{1}$ See Bresnahan (1989) and Roberts and Tybout (1996). Relatively small increasing returns to scale at the firm level are one of the reasons why, starting with Marshall (1890) and Young (1928), external returns (technological or linked to the specialization of industries) have been advanced as an explanation for the large effect of industrialization on aggregate income.
} 
Japan, and South Korea. Intermediate inputs' share of the value of total production also increased with industrialization in these countries. In Taiwan, it grew by approximately one percent annually and reached 61 percent in 1971. Chenery, Robinson, and Syrquin also observe that during their sample period intermediate-input use in both Taiwan and South Korea became similar to the pattern in more industrialized Japan, where 100 dollars of final demand in 1970 generated more than 80 dollars in intermediate-input demand. Their empirical analysis yields that the increase in the intermediate-input intensity of production during industrialization is mostly driven by changes in technology, although changes in final-goods demand also play a role. Furthermore, their data show that during industrialization productivity increases throughout input chains and that input-output matrices become much less sparse as sectors become more interdependent.

The goal of this paper is to develop a theory of industrialization that incorporates these two aspects of industrial technologies and re-examine the conclusions from the narrow view of industrialization (as adoption of industrial technologies in final-goods production only). Three main results emerge. First, if industrial technologies are intermediate-input intensive, then industrialization will have large effects on aggregate income and productivity, even if the degree of increasing returns to scale at the firm level is relatively small. This is because industrial technologies are adopted throughout input chains in the economy. The increase in aggregate productivity will therefore consist not only of the productivity-increase in final-goods production, but also the cumulated productivity-increase in the production of intermediate inputs used to produce final goods, of intermediate inputs used to produce intermediate inputs to produce final goods, and so on. Intermediate-input-intensive industrial technologies and input chains therefore provide a way to reconcile large effects of industrialization on aggregate income with relatively minor increasing returns to scale at the firm level. The second result of the analysis is that if industrial technologies are intermediate-input intensive relative to the technologies they replace, then industrializing firms may raise aggregate income even if they make a loss_-giving rise to a positive aggregate-income externality. This is because they increase profits of their intermediate-input suppliers 
and, through their suppliers' input demand, profits of their suppliers' suppliers, and so on. The third and main result of the paper is that if industrial technologies are sufficiently more intermediate-input intensive than the technologies they replace, then minor differences in the productivity of industrial technologies may be associated with large differences in equilibrium levels of industrialization, aggregate income, and aggregate productivity. Furthermore, a small improvement in the productivity of industrial technologies may trigger full-scale industrialization and a large increase in aggregate income and productivity. This will be the case even if industrial firms coordinate the adoption of industrial technologies.

\section{Related Literature}

The discussion of the role of input chains for industrialization dates back to Fleming's (1955) criticism of Nurkse (1952) and Rosenstein-Rodan (1943). Nurkse and Rosenstein-Rodan argue that the adoption of industrial technologies in the production of final goods could increase aggregate income even if the firms adopting these technologies were to make a loss. They also maintain that this could result in horizontal demand linkages among final-good producers, creating the need for coordinated adoption of industrial technologies - the big push - for industrialization to be profitable at the individual firm level. Fleming's point is that final-good firms adopting industrial technologies and making a loss will always subtract from, not add to, aggregate income under full-employment. Thus, if uncoordinated adoption of industrial technologies were unprofitable at the individual firm level, then coordinated adoption would neither be profitable for individual firms nor socially desirable. Fleming goes on to argue that vertical demand linkages that arise along input chains in the economy could however prevent socially desirable adoption of industrial technologies. Scitovsky (1954) and Hirschman (1958) make similar points.

A formal analysis of Fleming's argument about the role of horizontal demand linkages for the big push can be found in Murphy, Shleifer, and Vishny's (1989) analysis of industrialization. They first show that the narrow view of industrialization alone implies that equilibria are unique and socially efficient. As a result, the big push will not lead to equilibrium industrialization. Intuitively, this is because profits are the only 
channel of linkages in this case. They then extend their benchmark model to three mechanisms that give rise to multiple equilibria and therefore introduce a role for the big push: the industrial wage-premium asserted by Rosenstein-Rodan (1943); an intertemporal mechanism based on the timing of investment and cash flow; and the possibility of a large infrastructure investment that reduces industrial firms' cost of production. One of the ways to think of the present paper is as proposing an empirically motivated, alternative mechanism for the big push—although the main results do not rely on the existence of multiple equilibria.

The role of vertical linkages for economic development has been analyzed in Okuno-Fujiwara (1988) and Rodriguez-Clare (1996). They show how market structure and specialization in the intermediate-inputs sector can generate vertical linkages with the final-goods sector and result in multiple equilibria because of coordination failure. ${ }^{2}$ Neither input chains nor the intermediate-input intensity of industrial technologies play any role in their analysis however. Most closely related to the present paper are Fafchamps and Helms (1996) and Gans (1997, 1998a,b). They discuss the role of input chains and the intermediate-input intensity of industrial technologies for industrialization in open economies and in dynamic economies respectively, building on earlier versions of the present paper (Ciccone (1993a,b)).

\section{Industrialization with Input Chains}

The model of industrialization has two key features. First, each good can be produced with a constant-returns-to-scale or an increasing-returns-to-scale technology. The adoption of increasing-returns-to-scale technologies is referred to as industrialization. Second, production of all goods but one with the increasing-returns-to-scale technology requires intermediate inputs. This gives rise to input chains: goods are produced with intermediate inputs that are themselves produced with intermediate inputs.

\footnotetext{
2 Their argument is related to Murphy, Shleifer, and Vishny's (1989) infrastructure model where linkages also arise (indirectly) through lower costs of production. See Matsuyama (1995) for a review of models of multiple equilibria in economic development. The economic geography literature also analyzes vertical linkages, see Venables $(1995,1996)$ and Puga and Venables (1996). Puga and Venables consider a numerical multi-sector model to analyze the geographic spread of industry induced by technological change. The approach and context is very different from this paper and the aforementioned industrialization literature however.
} 


\subsection{The Economic Environment}

The commodities in the model are labor and a measure one of goods that can be consumed or used as inputs in production. All goods can be produced with two technologies: a constant-returns-to-scale, pre-industrial technology (PIT) and an increasing-returns-to-scale, industrial technology (IT). The PIT uses labor only and requires one unit of labor for each unit of output produced. Formally $y^{P}(m)=l^{P}(m)$ for all $m \in[0,1]$ where $y^{P}(m)$ denotes production of $\operatorname{good} m$ and $l^{P}(m)$ the amount of labor used to produce good $m$ with the PIT.

Production of good $m=0$ with the IT also requires labor only. The IT is $y^{I}(0)=(1 / \theta) \max \left[l^{I}(0)-f, 0\right]$ where $l^{I}(0)$ is the amount of labor used to produce good $m=0$ with the IT, and $f$ is the fixed input requirement of industrial production. It will be assumed throughout that $0<\theta<1$ and $f>0$. Hence, the IT for $m=0$ is subject to increasing returns to scale and more efficient at the margin than the corresponding PIT. Production of all goods $m>0$ with the IT requires labor and goods $i$ ranked strictly lower than $m$. The production function is $y^{I}(m)=(1 / \theta) \max [x(m)-f, 0]$ where $x(m)$ is a generalized input produced according to

$$
\log x(m)=\log B+\beta \log z(m)+(1-\beta) \log l^{I}(m), \quad 0<\beta<1,
$$

where $\log B=-\beta \log \beta-(1-\beta) \log (1-\beta)$ to ensure that all industrial firms have the same marginal cost of production in equilibrium. Intermediate inputs enter production with the IT through the intermediate-input composite $z(m)$, which is produced with all goods ranked lower than $m$ according to

$$
\log z(m)=\log m+\frac{1}{m} \int_{0}^{m} \log x(i, m) d i,
$$

where $x(i, m)$ is the quantity of good $i$ used as input in the (industrial) production of good $m$. This specification of the intermediate-input composite eliminates increasing returns to specialization as defined in Ethier (1982). To see this assume that all intermediate inputs can be purchased at the same price $(p)$. Then (2) implies that the production of intermediate-input composites relative to the cost of inputs is the same $(1 / p)$ in all sectors. Increasing returns to specialization would imply that production 
relative to the cost of inputs should be greater in sectors that use a larger variety of intermediate inputs.

The fact that production of each good $m>0$ with the IT requires all goods $i$ ranked strictly lower than $m$ gives rise to a triangular input-requirement structure. This structure is chosen because it is the simplest structure that gives rise to input chains while avoiding circular input-requirements. ${ }^{3}$ Goods ranked lower than $m$ will be referred to as goods produced upstream of $m$ and goods ranked higher as goods produced downstream of $m$.

Household preferences are

$$
U=\int_{0}^{1} \log c(m) d m
$$

Each household is endowed with one unit of labor and there is a measure $L$ of households in the economy.

There is a continuum of firms with access to the PIT to produce each good. These firms will be referred to as pre-industrial firms. The IT to produce each good is available to only one firm, referred to as industrial firm, and each industrial firm produces one good only. Both pre-industrial and industrial firms take prices in input markets as given. Different goods will be thought of as produced in different sectors. Sectors where production is undertaken by industrial (pre-industrial) firms will be referred to as industrial (pre-industrial) sectors. The assumed market structure implies that there is perfect competition among pre-industrial firms and that industrial firms set prices to maximize profits in their sector.

\subsection{Definition of Equilibrium and Equilibrium Prices}

Equilibria are defined by the following conditions:

\footnotetext{
${ }^{3}$ Setting up the model following the differentiated-input business-cycle literature by assuming that each intermediate input uses all other intermediate inputs in production (see Basu (1995) for example) would imply that, for any two intermediate inputs, the first input is required to produce the second and the second to produce the first. Production in such a model is a logical contradiction and it is therefore unclear what can be learnt from it.
} 
(I) The quantities of goods demanded by households maximize utility given prices of all goods and households' income.

(II) The quantities of goods produced in pre-industrial sectors and the quantities of labor these sectors demand are profit-maximizing choices of pre-industrial firms given the wage and prices of all goods.

(III) The prices of goods produced in industrial sectors and the quantities of inputs these sectors demand are profit-maximizing choices of industrial firms given the wage, upstream prices, downstream input-demand functions, and the consumption-demand function.

(IV) Industrial firms in industrial sectors do not make losses, and industrial firms in pre-industrial sectors would make losses if they were to produce.

(V) Quantities produced in each sector are equal to quantities demanded.

The assumptions about technology and preferences in (1)-(3) combined with the market structure imply that prices of all goods, whether they are produced in industrial or pre-industrial sectors, are identical in equilibrium.

Lemma 1. Prices of all goods are identical in equilibrium. Choosing labor as numeraire therefore implies that $p^{*}(m)=1$ for $m \in[0,1]$ where $p(m)$ is the price of good $m$ and asterisks denote equilibrium values.

Proof: The assumptions about technology and preferences in (1)-(3) imply that industrial firms face unit-elastic consumption-demand and input-demand functions. Hence, profit-maximization by industrial firms implies that-if industrial firms produce at all-they will set the largest price at which they cannot be undercut by pre-industrial firms in the same sector (assuming that consumers and producers buy from industrial firms at equal prices). The largest price at which industrial firms cannot be undercut is the marginal cost of production of pre-industrial firms. Pre-industrial firms transform labor into output one-to-one, which implies that their marginal cost of production is equal to the wage rate $w$. Choosing labor as numeraire therefore yields that all industrial firms in industrial sectors will set a price equal to unity. The price of goods produced in perfectly competitive, pre-industrial sectors will be equal to the marginal cost of pre- 
industrial firms, and hence also equal to unity. Thus, equilibrium prices are equal to unity in industrial and pre-industrial sectors. 


\subsection{The Industrialization Decision}

The production of the generalized input $x(m)$ in (1) is subject to constant returns to scale. Hence, the average cost of production is equal to the marginal cost $q(m)$ given by

$$
\log q(m)=\beta\left(\frac{1}{m} \int_{0}^{m} \log p(i) d i\right)+(1-\beta) \log w .
$$

Combined with equilibrium prices $p^{*}(m)=1$ for $m \in[0,1]$ and $w=1$ this implies that the average cost of producing $x(m)$ is unity. Hence, industrial firms that produce a quantity $y$ will incur a total cost of production $\theta(y+f)$ independently of the sector they produce in. Furthermore, (1) implies that it will be optimal for industrial firms to spend a fraction $\beta$ of their total cost of production to purchase upstream inputs.

Combining costs of production of industrial firms with equilibrium prices yields industrial firms' profits as a function of demand $y$,

$$
\pi=(1-\theta) y-\theta f .
$$

Industrial firms adopt the IT if demand is large enough for profits to be positive.

The choice of labor as numeraire yields that the marginal cost of production of pre-industrial firms is unity. Industrial firms' marginal cost of production is $\theta<1$. Hence, the marginal cost of production in pre-industrial sectors relative to industrial sectors is $1 / \theta$, which will be referred to as the relative (marginal) productivity of the IT. Furthermore, the price relative to the marginal cost of production in industrial sectors is also $1 / \theta$. Table 1 summarizes the interpretation of the parameters of the IT.

Table 1. Key Parameters of the Model

\begin{tabular}{|c|l|}
\hline Parameter & \multicolumn{1}{c|}{ Interpretation } \\
\hline $1>\beta>0$ & $\bullet$ Intermediate-input intensity of IT. \\
\hline$\frac{1}{\theta}>1$ & $\bullet \begin{array}{l}\bullet \text { Relative productivity of IT. } \\
\bullet \text { Price/marginal cost in sectors adopting the IT. }\end{array}$ \\
\hline$f>0$ & $\bullet$ Fixed input requirement of IT. \\
\hline
\end{tabular}




\subsection{Aggregate Income and Sectoral Demand}

Denote aggregate income when only the $n$ sectors furthest upstream have industrialized with $Y(n)$. It will become clear later that if a measure $n$ of sectors industrializes in equilibrium, then it will always be the sectors furthest upstream because they face the largest demand and therefore earn the highest profits. Furthermore, denote total demand for good $m$ when only the $n$ sectors furthest upstream have industrialized with $y(m, n)$. Demand for good $m$ and aggregate income are linked of course. The fact that equilibrium prices of all goods are equal to unity implies that households demand the same quantity $c(m)=Y(n)$ of all goods $m \in[0,1]$. Also, the PIT does not use intermediate inputs and the assumption that only the $n$ sectors furthest upstream have industrialized therefore implies that goods $m \geq n$ are not demanded as input in downstream sectors. This yields that goods produced in sectors downstream of $n$ are demanded for consumption only and hence that

$$
y(m, n)=Y(n), m \geq n .
$$

Goods $m$ upstream of $n$ are also demanded as inputs in downstream industrial sectors. It turns out that the only difference between the demand for good $m<n$ and the good just upstream of $m$ will be the quantity of the good just upstream demanded for production of good $m$. Demand for each good can therefore be determined recursively.

To be more precise notice that (2) assumes that all goods upstream of $m$ enter industrial production of good $m$ symmetrically. Combined with the result that all goods cost the same in equilibrium, this implies that industrial sector $m$ demands the same quantity of all upstream goods: $x(i, m, n)=v(m, n)$ for $i<m \leq n$ where $x(i, m, n)$ denotes demand for good $i$ as input in the production of good $m$ when only the $n$ sectors furthest upstream have industrialized. Hence, the total cost of intermediate inputs used to produce good $m$ with the IT is $m v(m, n)$, as the price of all goods is equal to unity in equilibrium. Furthermore, (1) implies that industrial firms spend a fraction $\beta$ of their total cost of production on intermediate inputs. Hence, total intermediate-input expenditures of industrial firms are $m v(m, n)=\beta \theta(y(m, n)+f)$. The demand for good $i<m$ as input in the production of good $m \leq n$ is therefore linked to total demand for good $m$ by $v(m, n)=\beta \theta(y(m, n)+f) / m$. 
Each industrial sector demands the same quantity of all upstream goods as inputs. Hence, each industrial sector downstream of $m$ demands the same quantity of good $m$ and the good just upstream of $m$. Consumers also demand the same quantity of good $m$ and the good just upstream. The difference between demand for good $m$ and the good just upstream is therefore $v(m, n)$, the quantity of the good just upstream demanded for production of good $m$. Market clearing in each sector yields that for $m<n$

$$
\frac{\partial y(m, n)}{\partial m}=-\theta \beta \frac{y(m, n)+f}{m} .
$$

Demand is therefore greater the further upstream the sector.

Demand for each sector $m<n$ can now be determined from (6) and (7) as $y(m, n)=(n / m)^{\theta \beta} Y(n)+\left((n / m)^{\theta \beta}-1\right) f$. Demand yields profits in each industrial sector using (5). Summing profits of all industrial firms and labor income yields aggregate income $Y(n)=L+\int_{0}^{n} \pi(m, n) d m$. This aggregate income identity can be solved for aggregate income when only the $n$ sectors furthest upstream have industrialized,

$$
Y(n)=\frac{L-\lambda f n}{\lambda n+(1-n)},
$$

where

$$
\lambda=\frac{1-\beta}{1 / \theta-\beta} .
$$

The next result proves that $\lambda$ is the average amount of labor required to produce one additional unit of each good $m \in[0, n]$ for consumption when all sectors upstream of $n$ use the IT; $\lambda$ will be referred to as the industrial labor requirement.

Lemma 2. Suppose that all sectors upstream of $n$ produce with the IT. Then the average amount of labor necessary to produce one additional unit of each good upstream of $n$ for consumption is equal to $\lambda$.

Proof: Denote with $\hat{y}(m, n)$ the additional amount of good $m$ necessary to produce one additional unit of each good upstream of $n$ for consumption. Using the argument behind (7) yields that $\hat{y}(m, n)$ satisfies $\partial \hat{y}(m, n) / \partial m=-\theta \beta \hat{y}(m, n) / m$. Furthermore, using the 
argument behind (6) yields $\hat{y}(n, n)=1$. Integrating these equations yields that $\hat{y}(m, n)=(n / m)^{-\theta \beta}$. The assumptions about the IT imply that each unit of output produced with the IT requires $\theta(1-\beta)$ units of labor. Hence, the total amount of labor necessary to produce one additional unit of each good upstream of $n$ for consumption is $\theta(1-\beta) \int_{0}^{n} \hat{y}(m, n) d m=\lambda n$ and the average amount of labor is $\lambda$.

With this understanding of $\lambda$ it becomes straightforward to interpret the expression for aggregate income in (8). The denominator is the average amount of labor required to produce one additional unit of each good for consumption if the $n$ sectors furthest upstream produce with the IT and the $1-n$ sectors furthest downstream produce with the PIT (the amount of labor required for each unit of output produced in pre-industrial sectors is unity). The aggregate marginal productivity of labor in producing consumption goods is therefore

$$
\text { Aggregate (Marginal) Productivity }=\frac{1}{\lambda n+(1-n)} .
$$

Furthermore, $\lambda f n$ in (8) is the amount of labor required to produce the fixed input requirements for the $n$ industrial sectors. Hence, aggregate income is equal to the labor available after production of the fixed input requirement for all industrial sectors multiplied by aggregate productivity.

\subsection{The Industrial Labor Requirement}

The two determinants of the industrial labor requirement can be readily identified from (9). First, the IT's relative productivity. Evidently, the greater $1 / \theta$, the smaller the industrial labor requirement. Second, the IT's intermediate-input intensity. The greater $\beta$, the smaller the industrial labor requirement. This is because the IT is not only used in the production of consumption goods upstream of $n$, but also in the production of inputs to produce these goods, of inputs to produce these inputs, and so on. Hence, the industrial labor requirement also reflects the cumulated productivity-increase in the production of inputs, which will be greater the more intensively intermediate-inputs are used in industrial production. 
To see the determinants of the industrial labor requirement at work in a simple example, suppose that there are only two sectors: an upstream sector and a downstream sector. Both sectors produce with the IT and have incurred the fixed cost. What is the average amount of labor necessary to produce one additional unit of both goods for consumption? The amount of labor and upstream good necessary to produce one additional unit of the downstream good are $(1-\beta) \theta$ and $\beta \theta$ respectively. The amount of labor necessary upstream to produce one additional unit of the upstream good for consumption and $\beta \theta$ units for downstream production is $\theta+\beta \theta^{2}$. Hence, the average amount of labor necessary to produce one additional unit of both goods for consumption is $\theta(1-(1-\theta) \beta / 2)$, which is decreasing in $1 / \theta$ and $\beta$.

In an economy with a large but finite number of sectors the amount of labor necessary to produce one additional unit of good $N \geq 2$ when all sectors use the IT is $\Omega(N)=\theta(1-\beta)+\theta \beta \Lambda(N-1)$ where $\Lambda(N-1)=\sum_{J=1}^{N-1} \Omega(J) /(N-1) \quad$ is the average amount of labor necessary to produce one additional unit of all goods upstream of $N$ (the industrial labor requirement upstream of $N$ ) and $\Omega(1)=\theta$. Combining these equations yields that the industrial labor requirement as a function of $N$ satisfies

$$
\Lambda(N)=\left(\frac{1-\beta \theta}{N}\right) \lambda+\left(1-\frac{1-\beta \theta}{N}\right) \Lambda(N-1)
$$

for $N \geq 2$ and $\Lambda(1)=\theta$. Hence, if $\lambda<\Lambda(N-1)$, then $\lambda<\Lambda(N)<\Lambda(N-1)$. This fact combined with $\Lambda(1)=\theta>\lambda$ implies that the industrial labor requirement $\Lambda(N)$ decreases with the number of sectors and tends to the industrial labor requirement of the continuum economy $\lambda$ as the number of sectors tends to infinity.

\subsection{Determinants of Aggregate Income}

It is evident that the increase in aggregate productivity and income implied by industrialization will be larger the greater the relative productivity of the IT. The effect of industrialization on aggregate productivity and income may however be large even if the productivity-increase in sectors adopting the IT is relatively small. This will be the case if the IT uses intermediate inputs sufficiently intensively. 
Lemma 3. Aggregate income and productivity in an economy where all goods are produced with the IT increases with the IT's intermediate-input intensity. Furthermore, the difference in aggregate income and productivity between an economy where all goods are produced with the IT and one where all goods are produced with the PIT becomes arbitrarily large as the IT's intermediate-input intensity tends to unity.

Proof: The easiest way to establish this result is by using (8) and (10) to determine aggregate productivity and income when all sectors use the PIT and IT respectively.

Table 2. Aggregate Productivity and Income

\begin{tabular}{|c|c|c|}
\hline & All sectors use the PIT & All sectors use the IT \\
\hline Aggregate Productivity & 1 & $1 / \lambda$ \\
\hline Aggregate Income & $L$ & $L / \lambda-f$ \\
\hline
\end{tabular}

Notes: The table makes use of (8) and (10).

Hence, the effect of industrialization on aggregate productivity and income is larger the smaller the industrial labor requirement $\lambda$. Furthermore, the difference in aggregate income and productivity between the economy where all goods are produced with the IT and the one where all goods are produced with the PIT becomes arbitrarily large as $\lambda \rightarrow 0$. The definition of the industrial labor requirement in (9) and $1 / \theta>1$ yields that $\lambda$ decreases with $\beta$ and that $\lambda \rightarrow 0$ as $\beta \rightarrow 1$.

A higher intermediate-input intensity of the IT increases aggregate productivity but not productivity of industrial firms because the price of intermediate inputs does not reflect the opportunity cost as upstream sectors are imperfectly competitive.

The aggregate productivity-increase implied by full industrialization $1 / \lambda-1$ is linked to the productivity-increase in each industrial sector $1 / \theta-1$ by

$$
1 / \lambda-1=\frac{1}{1-\beta}(1 / \theta-1) .
$$

Hence, input chains $(0<\beta<1)$ magnify the effect of the productivity-increase in each industrial sector on aggregate productivity. For example, a 10-percent productivityincrease in industrial sectors translates into a 33-percent aggregate productivity-increase 
when the intermediate-input intensity is 70 percent. Table 3 gives an idea of the effects of full-scale industrialization on aggregate productivity for reasonable values of the intermediate-input intensity in industrial sectors. ${ }^{4}$ For example, a 40-percent productivity-increase in industrial sectors translates into an aggregate productivityincrease of 100 percent if the intermediate-input intensity of the IT is 60 percent.

Table 3: Increase in Aggregate Productivity Implied by Industrialization

\begin{tabular}{|c|c|c|c|c|}
\hline & \multicolumn{4}{|c|}{ Intermediate-Input Intensity of IT ( $\boldsymbol{\beta})$} \\
\hline Productivity-Increase of IT (1/ $\boldsymbol{\theta}-\mathbf{1})$ & 0 & $50 \%$ & $60 \%$ & $70 \%$ \\
\hline $20 \%$ & $20 \%$ & $40 \%$ & $50 \%$ & $70 \%$ \\
\hline $40 \%$ & $40 \%$ & $80 \%$ & $100 \%$ & $130 \%$ \\
\hline $80 \%$ & $80 \%$ & $160 \%$ & $200 \%$ & $270 \%$ \\
\hline
\end{tabular}

Notes: The aggregate productivity-increase is $1 / \lambda-1$ where $\lambda$ is defined in (9).

Actual economies produce a finite number of goods. Hence, it is necessary to compare aggregate productivity in an economy with a finite number of sectors to aggregate productivity in the continuum economy (assuming in both cases that all sectors have industrialized). Aggregate productivity in an economy with $N$ sectors is the inverse of the industrial labor requirement $\Lambda(N)$, and aggregate productivity relative to the continuum economy is therefore $R(N)=\lambda / \Lambda(N)$. Table 4 calculates $R(N)$ assuming $1 / \theta=1.4$ and $\beta=0.6$.

Table 4: Relative Productivity with a Finite Number of Sectors

\begin{tabular}{|c|c|c|c|c|c|}
\hline Number of Sectors & 5 & 10 & 15 & 20 & 25 \\
\hline Productivity Relative to Continuum Economy & $90 \%$ & $92 \%$ & $93 \%$ & $94 \%$ & $95 \%$ \\
\hline
\end{tabular}

Notes: Relative productivity $R(N)=\lambda / \Lambda(N)$ is calculated using (9) and (11).

\footnotetext{
${ }^{4}$ For example, the average intermediate-input intensity of production in South Korea, Taiwan, and Japan is between 50 and 70 percent (Chenery, Robinson, and Syrquin (1986)). The average intermediate-input intensity in the US is around 60 percent (Bureau of Economic Analysis (1996)).
} 
Hence, aggregate productivity in the economy with a finite number of sectors is only 10 percent lower than in the continuum economy even if the number of sectors is small and input chains are rather short.

\subsection{Aggregate-Income Externalities and the Industrialization Multiplier}

The potentially large aggregate-income effect of industrialization makes it especially interesting to ask if this effect is internalized by industrial firms. The first step to answering this question is to calculate industrialization's marginal effect on aggregate income,

$$
Y^{\prime}(n)=\frac{(1-\lambda) Y(n)-\lambda f}{\lambda n+(1-n)}
$$

making use of (8). The numerator of (13) is equal to the amount of labor saved in the production of good $n$ and will be referred to as the direct impact of industrialization. Industrialization's marginal effect on aggregate income is therefore equal to the labor saved in the production of good $n$ multiplied by aggregate productivity. It is straightforward to show that the direct impact of industrialization on aggregate income is also equal to industrialization's effect on the profits of all industrial firms holding consumption demand constant. Rewriting the direct impact of industrialization using (5) yields

$$
\text { Direct Impact }=\frac{(1-\beta) \pi(n, n)+\beta(1-\theta) Y(n)}{1-\theta \beta} \text {, }
$$

where

$$
\pi(n, n)=(1-\theta) Y(n)-\theta f
$$

denotes profits of the industrial firm producing furthest downstream. Hence, there may be an aggregate-income externality associated with industrialization as the adoption of the IT may have a positive effect on aggregate income even if the industrializing firm makes a loss. ${ }^{5}$ This will be the case when the industrializing firm's losses are smaller than the increase in upstream profits owing to the increase in intermediate-input demand by the industrializing firm and by industrial firms producing intermediate inputs for the industrializing firm.

\footnotetext{
${ }^{5}$ Using (13) and (15) yields that this will be the case if $\lambda f /(1-\lambda)<Y(n)<\theta f /(1-\theta)$.
} 
It is clear from (13) that the total effect of industrialization on aggregate income exceeds its effect on profits holding consumption demand constant. This is because of what may be called the industrialization multiplier. This multiplier captures that the direct impact of industrialization on aggregate income increases demand for consumption goods and hence intermediate-input demand, profits, and aggregate income. To derive the multiplier formally suppose that demand for all consumption goods increases exogenously by one unit, and define $\hat{y}(m, n)$ as the implied increase in demand for good $m$ assuming that all sectors upstream of $n$ have industrialized. Notice that $\hat{y}(n, n)=1$ as goods $m \geq n$ are demanded for consumption only. Furthermore, the argument behind (7) yields $\partial \hat{y}(m, n) / \partial m=-\theta \beta \hat{y}(m, n) / m$ and hence $\hat{y}(m, n)=(m / n)^{-\theta \beta}$. This increase in demand raises profits in each industrial sector by $(1-\theta) \hat{y}(m, n)$ and aggregate income by $(1-\theta) \int_{0}^{n} \hat{y}(m, n) d m=(1-\lambda) n$. As a result of the increase in aggregate income, demand for all consumption goods increases by $(1-\lambda) n$, which generates additional intermediate-input demand, profits, and aggregate income. The implied increase in aggregate income is $((1-\lambda) n)^{2}$, which generates more demand for consumption goods and so on. The industrialization multiplier, $\sum_{k=0}^{\infty}((1-\lambda) n)^{k}=(\lambda n+(1-n))^{-1}$, is the total increase in aggregate income generated by an exogenous one-unit increase in the demand for all consumption goods.

\subsection{Industrialization in Equilibrium}

There are two types of locally stable equilibria: pre-industrial equilibria (PI-equilibria) where all goods are produced with the PIT, and full-industrialization equilibria (FIequilibria) where all goods are produced with the IT. Intuitively, equilibria are locally stable if profits in industrial sectors do not strictly increase (decrease) with a small increase (decrease) in the measure $n$ of sectors adopting the IT.

Lemma 4: There are two types of locally stable equilibria, PI-equilibria and FIequilibria. A PI-equilibrium exists if and only if

$$
f>\frac{(1-\theta) L}{\theta}
$$

and a FI-equilibrium exists if and only if 


$$
f<\left(\frac{1-\theta \beta}{1-\beta}\right) \frac{(1-\theta) L}{\theta} .
$$

Proof: A PI-equilibrium exists if and only if no industrial firm would make a strictly positive profit from adopting the IT when all sectors produce with the PIT, i.e. making use of (15) if and only if $\pi(0,0) \leq 0$. This last inequality is based on the fact that if all goods are produced with the PIT, then the industrial firm in sector $m>0$ makes the same profit or loss from adopting the IT than the industrial firm furthest upstream. It follows from (8) and (15) that $\pi(n, n)$ is continuous in $n$. Hence, $\pi(0,0)<0$ implies that there exists a $\delta>0$ such that $\pi(\varepsilon, \varepsilon)<0$ for all $0 \leq \varepsilon \leq \delta$ and therefore that the PIequilibrium is locally stable. Furthermore, (13) and (14) imply that $Y^{\prime}(0)>0$ if $\pi(0,0)=0$; hence, (15) implies that $\partial \pi(n, n) / \partial n$ evaluated at $n=0$ is strictly positive and that the PI-equilibrium is locally unstable. A locally stable PI-equilibrium therefore exists if and only if $\pi(0,0)<0$. Combining (8) and (15) yields (16). A FI-equilibrium exists if and only if no industrial firm makes a loss when all sectors produce with the IT. Notice that if $\pi(1,1) \geq 0$, then the industrial firm furthest downstream does not make a loss if all sectors produce with the IT. Furthermore, all industrial firms further upstream face greater demand and therefore earn strictly higher profits than the industrial firm furthest downstream. Hence, no industrial firm makes a loss if and only if $\pi(1,1) \geq 0$. Continuity of $\pi(n, n)$ in $n$ implies that the FI-equilibrium will be locally stable if $\pi(1,1)>0$. Moreover, (13) and (14) imply that $Y^{\prime}(1)>0$ if $\pi(1,1)=0$; hence, (15) implies that $\partial \pi(n, n) / \partial n$ evaluated at $n=1$ is strictly positive and that the FIequilibrium is locally unstable. A locally stable FI-equilibrium therefore exists if and only if $\pi(1,1)>0$. Combining (8) and (15) yields (17). To see that all interior equilibria are locally unstable notice that if $\pi\left(n^{*}, n^{*}\right)=0$ for $n^{*} \in(0,1)$, then (13) and (14) imply $Y^{\prime}\left(n^{*}\right)>0$; hence, (15) implies that $\partial \pi(n, n) / \partial n$ evaluated at $n^{*}$ is strictly positive and that the interior equilibrium is locally unstable.

\footnotetext{
${ }^{6}$ Equation (17) implies that there is a scale effect as a sufficiently large population translates into full-scale industrialization. As pointed out by a referee, this scale effect would disappear however if the fixed cost required for adoption of the IT was proportional to population.
} 
It is evident from (10) that aggregate productivity will always be greater in the FI-equilibrium than in the PI-equilibrium. The same is true for aggregate income.

Lemma 5: Aggregate productivity and income are greater in the FI-equilibrium than in the PI-equilibrium.

Proof: Aggregate productivity in the PI-equilibrium is unity and in the FI-equilibrium is $1 / \lambda>1$ using (10). Furthermore, (8) yields that aggregate income in the FI-equilibrium is $L / \lambda-f$ and that aggregate income in the PI-equilibrium is $L$. Notice that the condition for the FI-equilibrium to exist in (17) can be rewritten as $L / \lambda-f>\theta L / \lambda$, which implies $L / \lambda-f>L$ as $\theta>\lambda$. Hence, aggregate income in the FI-equilibrium is greater than in the PI-equilibrium.

It can be shown using (17) that aggregate income in the FI-equilibrium relative to the PI-equilibrium satisfies $Y(1) / Y(0)=1 / \lambda-f / L \in[\theta / \lambda, 1 / \lambda]$. Hence, aggregate income in the FI-equilibrium will be at least $\theta / \lambda>1$ times aggregate income in the PIequilibrium. The increase in aggregate income associated with full-scale industrialization will therefore be similar to the increase in aggregate productivity if the productivityincrease in industrial sectors is small. To get a sense of the magnitudes involved suppose that the productivity-increase in industrial sectors is 20 percent and that the intermediate-input intensity of industrial production 70 percent. Then the increase in aggregate income associated with industrialization will be between 40 and 70 percent (depending on $f / L$ ). If the productivity-increase in industrial sectors is 80 percent, then full-scale industrialization implies an increase in aggregate income between 170 and 270 percent.

Lemma 4 implies that there always exists a set of structural parameters where the PI-equilibrium and FI-equilibrium co-exist. In that case, industrial firms can raise their profits by coordinating adoption of the IT if the economy is in a PI-equilibrium because industrial firms' profits are always strictly greater in the FI-equilibrium than the PIequilibrium (where they do not produce). ${ }^{7}$ Lemma 5 implies that coordinating

\footnotetext{
${ }^{7}$ This also implies that the share of profits in income will be greater in the FI-equilibrium than in the PI-equilibrium.
} 
industrialization would not only increase profits of industrial firms but also aggregate income.

Proposition 1 summarizes the main result about industrialization.

Proposition 1. Minor differences in structural parameters may be associated with large differences in equilibrium levels of industrialization, aggregate productivity, and aggregate income if the IT is sufficiently intermediate-input intensive. This will be the case even if industrial firms coordinate their industrialization decisions.

Proof: Denote the set of all structural parameters $\sigma=(L, f, \theta, \beta)$ that satisfy $L>0$, $f>0,0<\theta<1,0<\beta<1$ with $\Sigma$, and the subset of structural parameters that satisfy $(1-\theta)(1-\theta \beta) L=\theta(1-\beta) f$ with $\Omega$. Notice that all $\omega \in \Omega$ satisfy (16). Furthermore, denote the $i$-th element of $\sigma, \omega$ with $\sigma^{i}, \omega^{i}$ respectively, and the set of all structural parameters $\sigma \in \Sigma$ that satisfy $\max \left\{\left|\sigma^{i}-\omega^{i}\right|: i=1, . ., 4\right\} \leq \varepsilon / 2$ for $\varepsilon>0$ and $\omega \in \Omega$ with $\mathrm{B}(\varepsilon, \omega)$. By construction, the structural parameters in $\mathrm{B}(\varepsilon, \omega)$ are close to each other in the sense that the maximum distance between any two structural parameters does not exceed $\varepsilon$. Furthermore, $\mathrm{B}(\varepsilon, \omega)$ contains structural parameters that satisfy (17) as well as structural parameters that satisfy (16) but not (17). Lemma 5 therefore implies that $\mathrm{B}(\varepsilon, \omega)$ contains structural parameters for which there is a unique PIequilibrium and structural parameters for which there is a FI-equilibrium. Lemma 4 yields that aggregate productivity and income is greater in the FI-equilibrium than in the PI-equilibrium. Finally, Lemma 3 implies that the difference in aggregate productivity and income between these equilibria becomes arbitrarily large for all sequences of $\omega \mathrm{s}$ that imply $\beta \rightarrow 1$. The argument remains unchanged if industrial firms coordinate their decision to adopt the IT. The only differences is that in this case the equilibrium is unique (there will be a FI-equilibrium if and only if (17) holds, and a PI-equilibrium if and only if (17) does not hold).

To understand this result it is useful to first assume that there are no input chains $(\beta=0)$. This case corresponds to the benchmark model of industrialization in Murphy, Shleifer, and Vishny (1989). ${ }^{8}$ Their results therefore imply that if there are no input

\footnotetext{
${ }^{8}$ Equilbria are both unique and socially efficient in their benchmark model.
} 
chains, then the FI-equilibrium will exist if and only if full-industrialization aggregate income exceeds aggregate income when all sectors adopt the PIT. Intuitively, this is because the private marginal cost of production $\theta$ is equal to the social marginal cost of production $\lambda$ in this case. If there are input chains $(1>\beta>0)$ however, then the private marginal cost of production $\theta$ is strictly greater than the social marginal cost of production $\lambda$. Hence, full-industrialization aggregate income must now be strictly greater than aggregate income when all sectors adopt the PIT for industrial firms to make a profit from the adoption of the IT.

One unsatisfactory feature of the model analyzed so far is that the PIT does not use intermediate inputs. It is however easy to allow for the PIT to use intermediate inputs and preserve all other features of the model at the same time. The extended model has the PIT using intermediate inputs in the same way as the IT, with the only difference that the PIT's intermediate-input intensity is $0<\alpha \leq 1$ while the IT's intermediate-input intensity is $0<\beta<1$. The appendix shows that the results derived for the case where the PIT does not use intermediate inputs generalize if and only if the IT uses intermediate inputs strictly more intensively than the PIT $(\beta>\alpha)$.

\subsection{The Role of the Industrial Technology}

Figure 1 uses (16) and (17) to relate the existence of PI-equilibria and FI-equilibria to the IT's intermediate-input intensity $\beta$ and the inverse of its relative productivity $\theta$.

\section{Figure 1. Full-Industrialization and Pre-Industrial Equilibria}

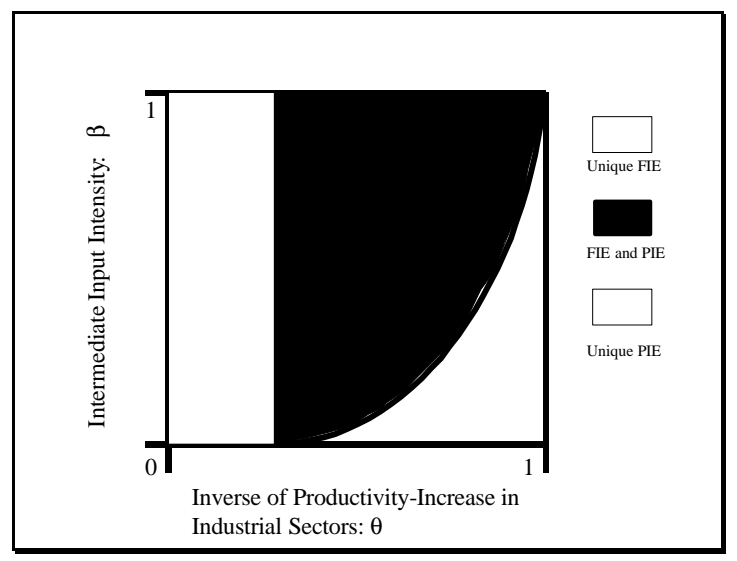

Notes: PIE (PI-equilibrium) and FIE (FI-equilibrium) denote values of $\theta$ and $\beta$ such that (16) and (17) hold respectively. 
Notice that the equilibrium is unique for most values of $\theta$ as long as $\beta$ is small. In particular, there will be a unique FI-equilibrium (PI-equilibrium) when the productivityincrease in industrial sectors is large (small). As $\beta$ increases, the region with unique equilibria shrinks and the region with multiple equilibria expands.

Figure 1 can be used to illustrate that minor differences in the productivity of the IT may be associated with large differences in equilibrium levels of industrialization and aggregate income. For example, one economy may have access to an IT that implies uniqueness of the FI-equilibrium. Another economy with access to an IT that is only slightly less productive may be in the PI-equilibrium. If the IT is sufficiently intermediate-input intensive, then the difference in the level of industrialization between the two economies will translate into a large difference in aggregate income. For example, suppose that the IT used in the industrialized economy is 80 percent more productive than the PIT and that the intermediate-input intensity of industrial production is 70 percent. Then aggregate income in the industrialized economy will be approximately three times aggregate income in the pre-industrial economy. ${ }^{9}$ Furthermore, it can also be seen from Figure 1 that a small improvement in the productivity of the IT may lead to a large increase in aggregate income. For example, consider a pre-industrial economy in the region where the FI-equilibrium and the PIequilibrium co-exist. Suppose that an improvement in the productivity of the IT takes this economy into the region with a unique FI-equilibrium. This will lead to an increase in aggregate income even if the technological improvement is small, and the implied increase in aggregate income will be large if the IT is sufficiently intermediate-input intensive.

If industrial firms coordinate the adoption of the IT, then economies will achieve full industrialization if and only if (17) holds. Figure 2 plots the equilibrium level of aggregate income against the inverse of IT's relative productivity in the case of coordinated industrialization.

\footnotetext{
9 These calculations combine that aggregate income in the FI-equilibrium relative to the PIequilibrium is $Y(1) / Y(0)=1 / \lambda-f / L$ and that (16) does not hold if the FI-equilibrium is unique. The latter yields the upper bound $(1-\theta) / \theta$ on $f / L$. This upper bound can be used to find the lower bound $1 / \lambda-(1-\theta) / \theta$ on aggregate income in the FI-equilibrium relative to the PI-equilibrium.
} 
Figure 2. Aggregate Income and Industrial Productivity

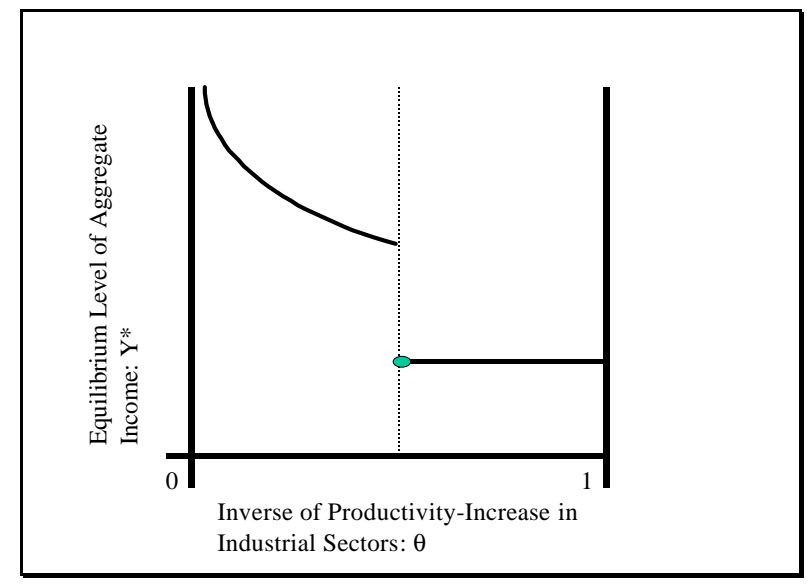

Notes: The figure assumes that the economy achieves full industrialization whenever a FI-equilibrium exists.

Hence, there is a critical point where a minor improvement in the productivity of the IT implies a relatively large increase in aggregate income (accompanied by full-scale industrialization). The increase in aggregate income at the critical point will be large if the IT is sufficiently intermediate-input intensive. To see this notice that the critical point $\hat{\theta}$ is defined by (17) with equality. Hence, $\hat{\theta} \rightarrow 1$ as $\beta \rightarrow 1$. Furthermore, aggregate income when all sectors produce with the IT evaluated at the critical point is $\hat{\theta f} /(1-\hat{\theta})$. The increase in aggregate income at the critical point will therefore become arbitrarily large as the IT's intermediate-input intensity tends to unity.

So far the focus has been on the role of the IT's relative productivity for industrialization and aggregate income. The fixed cost $f$ required for adoption of the IT plays an equally important and similar role however. For example, a minor drop in the fixed cost may trigger full-scale industrialization and a large increase in aggregate income. To see this suppose that industrial firms coordinate their industrialization decision and hence that the economy achieves a FI-equilibrium if and only if (17) holds. This implies that if the fixed cost required for the adoption of the IT falls below the critical level $\hat{f}=(1-\theta) L / \lambda$, then the economy goes from the PI-equilibrium to the FI-equilibrium. Aggregate income will increase as a result, and the increase in aggregate income will be large if the IT is sufficiently intermediate-input intensive. To see this notice that aggregate income when all sectors produce with the IT evaluated at the critical point is $\theta L / \lambda$ and that $\lambda \rightarrow 0$ as the IT's intermediate-input intensity tends to unity. 


\subsection{Efficient Industrialization and Economic Policy}

Industrialization is socially efficient if and only if aggregate income when all sectors use the IT exceeds aggregate income when all sectors use the PIT, i.e. $Y(1)>L$. To see how economic policy can play a role in achieving efficient industrialization, suppose that the economy is trapped in the PI-equilibrium because of coordination failure among industrial firms. In this case, economic policy can subsidize the adoption of the IT to achieve the critical mass of upstream industrial sectors necessary for industrialization to be profitable. This critical mass is implicitly defined by the lowest level of industrialization $n^{\prime}$ such that $\pi(n, n)>0$ for all $n>n^{\prime}$ and can be determined explicitly as $n^{\prime}=(\theta-(1-\theta) L / f) /(\theta-\lambda) \in(0,1)$ using (15)-(17). ${ }^{10}$ It is straightforward to show that the critical mass of industrial firms necessary for adoption of the IT to be profitable is decreasing in the IT's intermediate-input intensity. Hence, the greater the IT's intermediate-input intensity, the smaller the number of sectors that need to be subsidized.

Economic policy also plays a role for efficient industrialization when industrial firms coordinate the adoption of the IT. Coordination implies that the economy will achieve full industrialization if and only if $\pi(1,1)=(1-\theta) Y(1)-\theta f>0$, i.e. $Y(1)>(\theta / \lambda) L$ making use of (8). The private marginal cost of production of industrial firms exceeds the social marginal cost of production, $\theta>\lambda$, and industrial firms may therefore not adopt the IT although this would be socially efficient. Economic policy can ensure socially efficient industrialization by subsidizing intermediate-input purchases to the point where the cost to buyers is equal to the social marginal cost of production. This involves a subsidy $s=\theta-\lambda$ per unit bought. Such a subsidy implies that the economy will industrialize if and only if $\pi(1,1)=(1-(\theta-s)) Y(1)-(\theta-s) f>0$. Making use of (8) therefore yields that the economy will achieve full industrialization if and only if $Y(1)>L$. Hence, the subsidy implies that the economy will industrialize if and only if industrialization is socially efficient.

\subsection{Input Chains, General Purpose Technologies, and Productivity}

Input chains imply that technological improvements affecting many sectors simultaneously, a new General Purpose Technology (GPT) for example, will have large

\footnotetext{
${ }^{10}$ The critical mass $n^{\prime}$ is equal to the unique locally unstable equilibrium.
} 
effects on aggregate productivity if the IT is sufficiently intermediate-input intensive. For example, suppose that an economy is in the FI-equilibrium, that the intermediateinput intensity of the IT is 70 percent, and that a new GPT lowers the IT's marginal general-input requirement from $\theta=0.9$ to $\theta_{N}=0.82$. This amounts to a 10 -percent productivity-increase in sectors that adopt the new technology. Making use of (10) yields that if the new technology is adopted in all sectors of the economy, then the increase in aggregate productivity will be 26 percent. Interestingly, the implied increase in aggregate productivity may be large even if only a small fraction of sectors adopt a new GPT, as long as the adopting sectors are those furthest upstream. This result can be established formally with the help of the next proposition.

Proposition 2: Suppose that the economy is in the FI-equilibrium and that industrial sectors upstream of $u \in[0,1]$ produce with a more efficient IT than firms downstream of $u$. In particular, the marginal generalized-input requirement downstream of $u$ is $\theta$ while it is $\theta_{N}<\theta$ upstream of $u$. Then the average amount of labor required to produce one additional unit of each good for consumption is

$$
\lambda(u)=\lambda_{N} u^{1-\theta \beta}+\lambda\left(1-u^{1-\theta \beta}\right)
$$

where $\lambda_{N}=\theta_{N}(1-\beta) /\left(1-\theta_{N} \beta\right)$.

Proof: Denote with $\hat{y}(m, u)$ the additional production of good $m$ necessary to produce one additional unit of each good $m \in[0,1]$ for consumption. Using the argument behind (7) yields that $\hat{y}(m, u)$ satisfies $\partial \hat{y}(m, u) / \partial m=-\theta \beta \hat{y}(m, u) / m$ if $m>u$ and $\partial \hat{y}(m, u) / \partial m=-\theta_{N} \beta \hat{y}(m, u) / m$ if $m \leq u$. Furthermore, using the argument behind (6) yields $\hat{y}(1, u)=1$. Integrating these equations implies that $\hat{y}(m, u)=m^{-\theta \beta}$ for $m>u$ and $\hat{y}(m, u)=u^{\left(\theta_{N}-\theta\right) \beta} m^{-\theta_{N} \beta}$ if $m \leq u$. The assumptions about the IT imply that each unit of output requires $\theta(1-\beta)$ units of labor. Hence, the average amount of labor to produce one additional unit of each good $m \in[0,1]$ for consumption is $\theta(1-\beta) \int_{0}^{1} \hat{y}(m, u) d m=\lambda\left(1-u^{1-\theta \beta}\right)+\lambda_{N} u^{1-\theta \beta}$.

Evidently, the average amount of labor required to produce one additional unit of all goods for consumption decreases and aggregate (marginal) productivity $\rho(u)=1 / \lambda(u)$ increases as the new, more efficient IT is introduced in upstream sectors. Furthermore, 
aggregate productivity is a concave function of $u$ with $\rho^{\prime}(0)=\infty$. Hence, the increase in aggregate productivity is especially large when the more efficient technology is first introduced upstream. To get a sense of the magnitudes involved it is useful to return to the example where the intermediate-input intensity of the IT is 70 percent and the new IT lowers the marginal general-input requirement from $\theta=0.9$ to $\theta_{N}=0.82$. Recall that if all sectors adopt the new technology, then the aggregate productivity-increase is 26 percent in this case. The aggregate productivity-increase as a function of the fraction of upstream sectors adopting the new IT is given in Table 5.

Table 5: Increase in Aggregate Productivity

\begin{tabular}{|c|c|c|c|c|c|c|}
\hline Upstream Sectors Adopting New IT & $0 \%$ & $2 \%$ & $4 \%$ & $6 \%$ & $10 \%$ & $20 \%$ \\
\hline Aggregate Productivity-Increase & $0 \%$ & $6.8 \%$ & $8.5 \%$ & $10.1 \%$ & $12.2 \%$ & $16.8 \%$ \\
\hline
\end{tabular}

Notes: Calculations use (18) and $\beta=0.7, \theta=0.9$, and $\theta_{N}=0.82$.

The new technology will therefore raise aggregate productivity by 6.8 percent-more than a quarter of the aggregate productivity-increase implied by adoption in all sectorseven if it is adopted by only 2 percent of all sectors, as long as the adopting sectors are those furthest upstream. If the upstream sectors adopting the new technology amount to 10 percent of all sectors, then the aggregate productivity-increase is more than 45 percent of the aggregate productivity-increase implied by full adoption.

\section{Summary}

The widespread adoption of increasing-returns-to-scale, industrial, technologies as a key aspect of industrialization has been emphasized in both the theoretical and empirical literature on industrialization. The theoretical literature has however neglected two aspects stressed in the empirical literature. First, industrial technologies are adopted throughout input chains in the economy. Second, industrial technologies are more intermediate-input intensive than the technologies they replace. This paper has analyzed the implications of these two aspects of industrial technologies for industrialization. Two interesting results emerged from the analysis. First, industrialization's effect on aggregate income and productivity may be large even if increasing returns at the firm level are small. Second, minor improvements in the productivity of industrial technologies may trigger full-scale industrialization and a large increase in aggregate 
income and productivity. This will be the case even if industrial firms coordinate their decisions to adopt industrial technologies. 


\section{References}

Basu, Susanto (1995), "Intermediate Goods and Business Cycles: Implications for Productivity and Welfare,” American Economic Review, June.

Bresnahan, Timothy (1989), "Empirical Studies of Industries with Market Power," in Richard Schmalensee and Robert Willig (eds.), Handbook of Industrial Organization, Amsterdam, North-Holland.

Bureau of Economic Analysis (1996), “Annual Input-Output Accounts of the U.S. Economy," Washington D.C.

Ciccone, Antonio (1993a), "The Acceleration Principle, Income Generation, and Industrialization," Mimeo, Stanford University, February.

Ciccone, Antonio (1993b), "The Statics and Dynamics of Industrialization and Specialization," Mimeo, Stanford University, February.

Chenery, Hollis, Sherman Robinson, and Moshe Syrquin (1986), Industrialization and Growth: A Comparative Study, New York, Oxford University Press.

Ethier, Wilfred (1982), "National and International Returns to Scale in the Modern Theory of International Trade," American Economic Review, June.

Fafchamps, Marcel and Brigit Helms (1996), "Local Demand, Investment Multipliers, and Industrialization: Theory and Application to the Guatemalan Highlands," Journal of Development Economics, April.

Fleming, Marcus (1955), "External Economies and the Doctrine of Balanced Growth," Economic Journal, June.

Gans, Joshua (1997), "Fixed Cost Assumptions in Industrialization Theories," Economic Letters, September.

Gans, Joshua (1998a), "Time-Lags and Indicative Planning in a Dynamic Model of Industrialization,” Journal of the Japanese and International Economies, June.

Gans, Joshua (1998b), "Industrialization with a Menu of Technologies: Appropriate Technologies and the 'Big Push'," Structural Change and Economic Dynamics, September.

Hirschman, Albert (1958), The Strategy of Economic Development, Yale University Press, New Haven.

Marshall, Alfred (1890), Principles of Economics, Macmillan, London.

Matsuyama, Kiminori (1995), "Complementarities and Cumulative Processes in Models of Monopolistic Competition,” Journal of Economic Literature, June.

Murphy, Kevin, Andrei Shleifer, Vishny (1989), "Industrialization and the Big Push," Journal of Political Economy, May. 
Nurkse, Ragnar (1952), "Growth in Underdeveloped Countries," American Economic Review, May.

Okuno-Fujiwara, Masahiro (1988), "Interdependence of Industries, Coordination Failure, and Strategic Promotion of an Industry, Journal of International Economics, August.

Puga, Diego and Anthony Venables (1996), "The Spread of Industry: Spatial Agglomeration in Economic Development," Journal of the Japanese and International Economies, December.

Roberts, Mark and James Tybout (1996), Industrial Evolution in Developing Countries, Oxford, Oxford University Press.

Rodriguez-Clare, Andres (1996), "The Division of Labor and Economic Development," Journal of Development Economics, April.

Rosenstein-Rodan, Paul (1943), "Problems of Industrialization of Eastern and SouthEastern Europe,” Economic Journal, June.

Scitovsky, Tibor (1954), "Two Concepts of External Economies,” Journal of Political Economy, September.

Venables, Anthony (1995), "Economic Integration and Location of the Firm," American Economic Review, May.

Venables, Anthony (1996), "Trade Policy, Cumulative Causation, and Industrial Development," Journal of Development Economics, April.

Young, Allyn (1928), "Increasing Returns and Economic Progress," Economic Journal, December. 


\section{Appendix: Model where the Pre-Industrial Technology Uses Intermediate Inputs}

The PIT for the good furthest upstream uses labor only and requires one unit of labor for each unit of output produced. The PIT for goods $m>0$ is

$$
\log y^{P}(m)=\log A+\alpha \log z^{P}(m)+(1-\alpha) \log l^{P}(m), \quad 0<\alpha \leq 1
$$

where $\log A=-\alpha \log \alpha-(1-\alpha) \log (1-\alpha)$ to ensure that prices of all intermediate inputs will be identical in equilibrium; $z^{P}(m)$ is the quantity of intermediate-input composites used in the production of good $m$ with the PIT. This specification of the PIT implies that the marginal and average cost of production of pre-industrial firms in sector $m$, $q^{P}(m)$, is

$$
\log q^{P}(m)=\alpha\left(\frac{1}{m} \int_{0}^{m} \log p(i) d i\right)+(1-\alpha) \log w
$$

\section{Definition of Equilibrium and Equilibrium Prices}

Equilibria are defined as in the main text with the addition that the inputs demanded by pre-industrial sectors must be profit-maximizing choices of pre-industrial firms.

To determine equilibrium prices, notice that (A1) and (1)-(3) in the main text imply that industrial firms face unit-elastic consumption-demand and input-demand functions. Hence, profit-maximization by industrial firms implies that-if industrial firms produce-they will set the largest price at which they cannot be undercut by preindustrial firms in the same sector. The largest price at which industrial firms cannot be undercut is the marginal cost of production of pre-industrial firms. Pre-industrial firms' marginal cost of production can be determined recursively, starting with pre-industrial firms in the sector furthest upstream. These firms require one unit of labor for each unit of output and their marginal cost is therefore equal to the wage, which is normalized to unity. As a result, the industrial firm furthest upstream will set its price equal to unity if it produces, $p^{I}(0)=1$. Now consider pre-industrial firms just downstream of sector $m=0$. Their marginal cost of production in (A2) is unity. The corresponding industrial firm will therefore set its price equal to unity if it produces. Applying the same argument 
to firms further downstream yields $q^{P}(m)=1$ in all sectors and $p^{I}(m)=1$ in all industrial sectors. Hence, equilibrium prices are equal to unity in all sectors.

\section{Aggregate Income and Aggregate-Income Externalities}

Demand for each good is derived as in the main text. The main difference is that (7) is replaced by

$$
\frac{\partial y(m, n)}{\partial m}= \begin{cases}-\theta \beta(y(m, n)+f) / m & \text { if } m<n \\ -\alpha y(m, n) / m & \text { if } m \geq n\end{cases}
$$

where $\alpha y(m, n) / m$ captures the intermediate-input demand of pre-industrial sectors. Equation (6) in the main text is replaced by $y(1, n)=Y(n)$, as only the good furthest downstream is not used as an input in any other sector. Using the argument in the main text yields aggregate income

$$
Y(n)=(L-\lambda f n) /\left(1-n^{1-\alpha}+\lambda n^{1-\alpha}\right)
$$

where $\lambda$ is defined in (9) in the main text. Notice that $\alpha>0$ implies that, compared to the case where the PIT does not use intermediate inputs in (8), greater weight is put on the industrial labor requirement. This is because some of the inputs of pre-industrial sectors are now produced with the IT. Aggregate income in the FI-equilibrium is $L / \lambda-f$.

Profits of the industrial firm furthest downstream when the $n$ sectors furthest upstream have industrialized are

$$
\pi(n, n)=(1-\theta) y(n, n)-\theta f,
$$

where $y(n, n)$, the demand for the good produced in sector $n$ when the $n$ sectors furthest upstream have industrialized, is

$$
y(n, n)=Y(n) n^{-\alpha}
$$

The expression corresponding to (13) is

$$
Y^{\prime}(n)=((1-\alpha)(1-\lambda) y(n, n)-\lambda f) /\left(\lambda n^{1-\alpha}+\left(1-n^{1-\alpha}\right)\right)
$$

with the interpretation given in the main text. The numerator of (A7) can be rewritten as

$$
\text { Direct Impact }=\lambda \pi(n, n) / \theta+(1-\lambda)(\beta-\alpha) y(n, n) .
$$


Hence, there will be a positive income externality of industrialization only if $\beta>\alpha$.

\section{Equilibrium Industrialization}

It follows directly from (A5) and (A6) that $\alpha>0$ implies that $\pi(0,0)>0$ and hence that there is no PI-equilibrium. This is because the input demand of pre-industrial firms implies that demand for goods produced furthest upstream will always be large enough for the IT to be profitable. The PI-equilibrium is replaced by the low-industrialization equilibrium (LI-equilibrium) where all goods upstream (downstream) of some sector $n^{*} \in(0,1)$ are produced with the IT (PIT).

The two main results are summarized next.

Proposition A1: If $\alpha \leq \beta$, then the equilibrium is unique and aggregate income is a continuous function of structural parameters.

Proof: It follows from (A5)-(A8) that $\beta \leq \alpha$ implies that if $\pi(n, n)<0$, then $\pi(m, m)<0$ for $m>n$. It is therefore natural to consider the following three cases separately to prove uniqueness. First, $\pi(n, n)>0$ for all $n \in(0,1)$, which implies that there is a unique FI-equilibrium. Second, that $\pi(n, n)$ becomes strictly negative for some $n \in(0,1)$. In this case there is a unique LI-equilibrium because $\pi(n, n)$, once strictly negative, remains so as $n$ increases. The third possibility is that $\pi(n, n) \geq 0$ for all $n \in(0,1)$ and $\pi(n, n)=0$ for some $n \in(0,1)$. In this case, there would be multiple equilibria, a locally stable FIequilibrium and a locally unstable LI-equilibrium. To see that this is impossible notice that (A4)-(A6) imply that there will be a locally unstable LI-equilibrium if and only if $v(n)=0$ for some $n \in(0,1)$ and $v(n) \geq 0$ for all $n$, where

$$
v(n)=(1-\theta) L n^{-\alpha}+(\theta-\lambda) f n^{1-\alpha}-\theta f
$$

is U-shaped. Furthermore, there will be a FI-equilibrium if and only if $v(1) \geq 0$. The FIequilibrium and the locally unstable LI-equilibrium will co-exist if and only if $\min v(n)=0$ and $0<\operatorname{argmin} v(n)<1$. Straightforward algebra establishes that these conditions can never be satisfied simultaneously if $\beta \leq \alpha$.

The LI-equilibrium and FI-equilibrium depend continuously on the structural parameters of the model. Hence, for there to be a discontinuity, there must be structural parameters where a small perturbation causes a jump from the LI-equilibrium to the FI-equilibrium 
or vice-versa. For this to be the case either (a) or (b) must hold: (a) $\min v(n)=0$ and $\operatorname{argmin} v(n)<1$. In this case, there is a LI-equilibrium and a small perturbation of the parameters such that $\min v(n)>0$ would cause the LI-equilibrium to disappear. But $\min v(n)=0$ and $\operatorname{argmin} v(n)<1$ imply $v(1)>0$ and hence that there would also be a FIequilibrium. This is impossible as the equilibrium is unique. (b) $v(1)=0$. In this case, there is a FI-equilibrium and a small perturbation of structural parameters such that $v(1)<0$ will cause the FI-equilibrium to disappear. If $\operatorname{argmin} v(n) \geq 1$, then the equilibrium will go continuously from a FI-equilibrium to a LI-equilibrium as $v(n)$ depends continuously on the parameters and is U-shaped. If $v(1)=0$ and $\operatorname{argmin} v(n)<1$, then the equilibrium would jump from a FI-equilibrium to a LI-equilibrium. But these conditions can never be satisfied simultaneously as the equilibrium is unique.

Proposition A2: If $\beta>\alpha$, then there is a set of structural parameters for which there will be multiple locally stable equilibria.

Proof: It is straightforward to show using (A5)-(A8) that there is at most one LIequilibrium. This implies that for there to be multiple locally stable equilibria, the locally stable LI-equilibrium and FI-equilibrium must co-exist. This will be the case if $v(1)>0$, $\min v(n)<0$, and $\operatorname{argmin} v(n)<1$. It can be shown using (A9)-(A11) that there is a set of structural parameters of strictly positive measure satisfying these conditions if and only if $\beta>\alpha$.

When there are multiple equilibria, profits of industrial firms and aggregate income in the FI-equilibrium are strictly greater than in the LI-equilibrium. It is therefore straightforward to prove the equivalent of Proposition 1 for the model where the PIT uses intermediate inputs if $\beta>\alpha$. 